\title{
Deríscope.
}

\section{CLINICAL NEUROLOGY.}

Periphieral Neuritis following the Use of Arsentc in Chorea. F. C. Railton (Medical Chronicle, February, I900).

This study is based on four patients with chorea treated by arsenic at the Manchester Clinical Hospital, in whom serious symptoms of paralysis developed. The ordinary toxic symptoms of arsenic; disturbance of the stomach, diarrhea, puffiness of the eyes, etc., were noticed in only one of the patients, and the paralysis, which affected the lower extremities principally, came on gradually several days or even weeks after termination of treatment, and in most instances after the return of the patient home. All the patients eventually recovered after a protracted convalescence. Because of the slow elimination of this metal from the system, the author concludes that an aggregate of 6.3 grains of arsenious acid, even when distributed over a period of three weeks, is sufficient to produce peripheral neuritis in a child.

JELLIFFE.

Zur Symptomatik der Geschiwülste des Balkens (Symptomatology of Tumors of the Corpus Callosum). H. Zingerle (Jahrbücher für Psychiatrie und Neurologie, Vol. I9, I900, p. 367).

Clinical history: Man fifty years old. Beginning of symptoms seven weeks before with sudden dulling of consciousness, stupor, inability to stand erect, weakness in legs, sleepiness, and mental confusion. Jresent condition: somnolent, confused, marked amnesia, mental weakness, expression fixed, speech slow, no aphasia, slow pupil reaction, bilateral optic neuritis, tremor of tongue, weakness in all extremities, inability to stand or walk, increased reflexes, then fever, muscle spasm, progressive weakness in muscles more marked on the right side, exitus. Autopsy: Dura adherent, pia somewhat stretched, thickened here and there, hyperemic. The corpus callosum bulged in its middle and of a reddish color. On opening the lateral ventricle in a line corresponding with the middle of the corpus callosum a tumor mass, $4 \mathrm{cc}$. long and $3 \mathrm{cc}$. broad was found. This tumor is of firm consistency and reddish in color. The mass extends in front to the septum pellucidum and bulges laterally into the lateral ventricles in consequence of which they appear somewhat narrowed, as is likewise the case in the third ventricle. The ependyma of the corpus callosum appears somewhat thickened, the brain substance soft, somewhat hyperemic, the cortex somewhat small, with widened sulci. In other organs nothing abnormal. The tumor was diagnosed as a round-cell sarcoma, rich in blood vessels. The anatomical findings showed clearly that the tumor developed at the region of the right taenia of the thalamus opticus, and secondarily involved the corpus callosum. Some of the clinical features of a tumor in this region are as follows: The absence of pressure symptoms other than that of optic atrophy which is found more often in callosal tumors than elsewhere. A slight paresis of the muscles together with an absence of crania! nerve involvement. The paresis is due to the pressure on the motor tract in the internal capsule. The one 